\title{
Serotonin Subtype 2 Receptor Genes and Clinical Response to Clozapine in Schizophrenia Patients
}

\author{
Mario Masellis, B.Sc., M.Sc., Vincenzo Basile, Herbert Y. Meltzer, M.D., Jeffrey A. Lieberman, M.D., \\ Serge Sevy, M.D., Fabio M. Macciardi, M.D., Ph.D., Phil Cola, M.A., Alfreda Howard, M.A., \\ Farideh Badri, B.Sc., Markus M. Nöthen, M.D., Werner Kalow, M.D., \\ and James L. Kennedy, M.Sc., M.D.
}

Using a pharmacogenetic approach in 185 schizophrenics who have been prospectively assessed for clozapine response, we have examined the hypothesis that polymorphisms in the 5-HT2A (HTR2A), and 5-HT2C (HTR2C) genes are involved in its variable response. $A-1438 A \rightarrow G$ polymorphism in the putative promoter and a silent $T \rightarrow C$ 102 substitution in HTR2A were in almost complete linkage disequilibrium, and neither was associated with response ( $T \rightarrow C$ C 102 allele: $\chi^{2}=0.02 ; 1 d f, \mathrm{p}=.90$; genotype: $\left.\chi^{2}=0.02,2 d f, \mathrm{p}=.99\right)$. A his452tyr HTR2A polymorphism was found to be associated with clozapine response (his452tyr allele: $\chi^{2}=6.43,1 \mathrm{df}, \mathrm{p}=.01[\mathrm{p}=.04$, Bonferroni corrected]; genotype: $\chi^{2}=6.54,2 d f, \mathrm{p}=.04$
[ $\mathrm{p}=.16$, Bonferroni corrected]). No HTR2A haplotype was associated with response. Interethnic differences were observed in the frequencies of the cys23ser HTR2C polymorphism. This polymorphism was not significantly associated with response in either of the ethnic groups (Caucasian and African American genotype: $\chi^{2}=3.46,2$ $d f, \mathrm{p}=.18 ; \chi^{2}=.31,2 d f, \mathrm{p}=.86$, respectively). Although replication is required, the overall results suggest that the his452tyr HTR2A polymorphism may be involved in clozapine response. [Neuropsychopharmacology 19:123-132] (c) 1998 American College of Neuropsychopharmacology. Published by Elsevier Science Inc.
KEY WORDS: Clozapine response; Pharmacogenetic; 5-HT2A; 5-HT2C; Receptor; Polymorphism

From the Neurogenetics Section (MM, VB, FMM, FB, JLK), Clarke Institute of Psychiatry, University of Toronto, Toronto, Ontario, Canada; Department of Psychiatry (HYM), Vanderbilt University, Nashville, Tennessee; Department of Psychiatry (JAL), University of North Carolina, Chapel Hill, North Carolina; Department of Veteran Affairs (SS), Bronx VA, New York, New York; Department of Psychiatry (PC), Case Western Reserve University, Cleveland, Ohio, USA; Department of Psychiatry (AH), Hillside Hospital, Glen Oaks, New York; Institute of Human Genetics (MMN), University of Bonn, Bonn, Germany; Department of Pharmacology (MM, WK), University of Toronto, Toronto, Ontario, Canada.

Address correspondence to: Dr. J. L. Kennedy, R-31, Neurogenetics Section, Clarke Institute of Psychiatry, 250 College St., Toronto, Ontario, Canada M5T 1R8.

Received 3 September 1997; revised 24 November 1997; accepted 3 December 1997
Clozapine, the prototype of atypical antipsychotic drugs, has been reported to have a variety of clinical advantages for treatment of schizophrenia as compared to typical antipsychotic drugs (Meltzer 1995a). As with all antipsychotic agents, the response to clozapine ranges from none to extensive. Up to $60 \%$ of patients refractory or intolerant to typical antipsychotic therapy are significantly improved by clozapine (Bleehen 1993). This observed variability in response has stimulated interest in identifying predictors of response to clozapine (Meltzer 1996). Identification of one or several variables that can reliably predict clozapine's response could influence the decision about on whom to initiate treatment and the duration of a clinical trial.

There is strong evidence for a threshold for plasma clozapine levels to achieve good response. It was found 
that plasma concentrations should equal or exceed 350 to $400 \mathrm{ng} / \mathrm{ml}$ to achieve a high rate of response (Lindenmayer and Apergi 1996). Several studies have demonstrated that there is a great deal of interindividual variability in clozapine's pharmacokinetics (Dahl et al. 1994; Choc et al. 1990; Thorup and Fog 1977; Bondesson and Lindstrom 1988; Cheng et al. 1988). Steady-state plasma concentrations of clozapine vary widely between patients treated with the same oral dose. These results suggest that pharmacokinetic factors may play a role in the observed interindividual variability in response to clozapine.

Traditionally, pharmacogenetic factors based on genetic variation in enzymes that metabolize a drug account for much of the variability in the response and/or side-effect profile of that drug (Kalow 1986). This paradigm can account for variability in response and side effects to several classes of drugs, including typical antipsychotics and antidepressants. Several of these psychotropic agents are metabolized by the polymorphic cytochrome-P450 2D6 (CYP2D6) enzyme (Cholerton et al. 1992; Dahl and Bertilsson 1993). This same paradigm may also be applicable to clozapine, because preliminary evidence suggests that genetic factors may be involved in the interindividual variability observed in its response. A recent study has identified monozygotic twins who were concordant for both neuroleptic resistance and response to clozapine (Vojvoda et al. 1996).

There has been consistent evidence that the cytochrome-P450 isoenzyme, CYP1A2, plays a significant role in the metabolism of clozapine (Jerling et al. 1994; Bertilsson et al. 1994; Odom-White and De Leon 1996). However, to date, no polymorphisms at this locus have been found (Nakajima et al. 1994). In light of these studies and the lack of polymorphic variation at CYP1A2, it is unlikely that response to clozapine can be predicted using only the traditional pharmacogenetic paradigm of genetic variability in major drug metabolizing enzymes. Nevertheless, this possibility may not be fully excluded without further study. It is also possible that polymorphisms in genes that encode regulators of CYP1A2 expression may be involved.

Central pharmacodynamic factors are likely determinants of interindividual variation in response to clozapine. Several have suggested that genetic factors may contribute to differences in pharmacodynamic response to clozapine (Kennedy 1994; Kerwin et al. 1994; Propping and Nöthen 1995). Genetic variation in genes that encode receptor proteins for which clozapine has affinity could account for variation in response.

As compared to typical antipsychotic medications, clozapine has a high affinity for receptors from many different neurotransmitter systems. The cloning of the dopamine D4 receptor and the discovery that clozapine was approximately 10-fold more selective for the D4 receptor than for the D2 receptor (Van Tol et al. 1991) made it a good initial candidate gene to test in examining the pharmacogenetics of clozapine. Several studies of genetic variability in the D4 receptor gene (DRD4) and response to clozapine have produced negative findings (Shaikh et al. 1993; Rao et al. 1994; Shaikh et al. 1995; Rietschel et al. 1996; Badri et al. 1996; Kohn et al. 1997).

There is considerable interest in the role of serotonin receptors in the mechanism of action of clozapine (Meltzer and Nash 1991). In particular, two of the serotonin 2 receptor subtypes; namely, 5-HT2A and 5-HT2C, that clozapine antagonizes with high affinity, have been implicated.

5-HT2A/2C agonists possess potent hallucinogenic properties in humans that are highly correlated with their affinities for both receptors (Glennon et al. 1984); thereby, suggesting that these receptors may play a role in psychosis, although visual hallucinations are rare in schizophrenia. Meltzer and colleagues have hypothesized that some of the clinical advantages of clozapine and other atypical antipsychotics, especially those related to EPS and negative symptoms, may be attributable to their significantly higher affinity for 5-HT2A receptors relative to their affinity for D2 receptors (Meltzer 1989a; Meltzer and Nash 1991; Meltzer 1994; 1995a). 5-HT2C receptors have also been implicated (Canton et al. 1990; Kahn et al. 1993). Furthermore, 5-HT2A/2C antagonists, such as ritanserin and mianserin, may be useful when added to typical antipsychotic therapy (Bersani et al. 1986; Wiesel et al. 1994; Rogue and Rogue 1992).

The localization of 5-HT2A and 5-HT2C receptors in the central nervous system is consistent with neuroanatomical structures believed to be involved in the pathophysiology of schizophrenia. 5-HT2A receptors are located on pyramidal neurons in many areas of the frontal cortex as well as some parts of the limbic system, particularly the olfactory nuclei, and parts of the basal ganglia. 5-HT2C receptors, although predominantly found in the choroid plexi, are also distributed in areas of the limbic system, and regions associated with motor behavior (Hoyer et al. 1994).

Arranz et al. (1995) have reported an allelic association between a thymidine to cytosine $(\mathrm{T} \rightarrow \mathrm{C})$ silent polymorphism within the coding region of the 5-HT2A receptor gene (HTR2A), located on chromosome 13, and clinical response to clozapine in patients suffering from schizophrenia. They found that the genotype C102/ C102 was more common in patients who did not respond to clozapine than in those who did respond. An allelic association was also reported between a polymorphism in the 5-HT2C receptor gene (HTR2C), located on the $\mathrm{X}$ chromosome, and clozapine response (Sodhi et al. 1995). This polymorphism causes a cysteine to serine amino acid substitution at position 23 (cys23ser) in the 5-HT2C receptor protein. Sodhi et al. found that 
the presence of at least one ser23 allele was more common in patients who responded to clozapine than in those who did not.

In our current study, we employed a genetic association strategy to assess four polymorphisms (three in the serotonin $2 \mathrm{~A}$ receptor gene and one in the serotonin $2 \mathrm{C}$ receptor gene) in a large, well-characterized sample of clozapine-treated schizophrenia patients who were prospectively assessed for response to this atypical antipsychotic. The HTR2A polymorphisms are: (1) a histidine to tyrosine amino acid substitution at position 452 (his452tyr); (2) a novel adenine to guanine $(A \rightarrow G)$ polymorphism at position -1438 in the putative promoter region; and (3) we have extended our previous study of the $\mathrm{T} \rightarrow \mathrm{C} 102$ polymorphism in prediction of clozapine response (Masellis et al. 1995). For the HTR2C gene, we analyzed the cys23ser polymorphism to determine its contribution in predicting response to clozapine.

\section{MATERIALS AND METHODS}

\section{Clinical Sample}

Clinical data from patients with DSM-III-R diagnoses of schizophrenia and meeting the criteria for treatmentrefractoriness or intolerance to typical antipsychotic therapy (Kane et al. 1988) were obtained at the following research clinics: Case Western Reserve University in Cleveland, Ohio (HY Meltzer, $n=105)$; Hillside Hospital in Glen Oaks, New York (JA Lieberman, $n=65$; and Bronx VA, New York (S Sevy, $n=16$ ). See Table 1 for the demographic distribution of the patients from each of the clinical sites. After informed consent was obtained, the patients underwent a wash-out period of 2 to 4 weeks during which, unless clinically necessary, they received no medications before starting clozapine. Clozapine treatment was continued for a minimum of 6 months, during which patients were followed prospec- tively. Clozapine blood levels were also monitored throughout the course of the treatment to ascertain compliance.

Treatment response was evaluated at 6 months or more using criteria based on those of Kane et al. (1988) in their study of the efficacy of clozapine vs. chlorpromazine in treatment-refractory schizophrenia: a reduction of $\geqslant 20 \%$ in the Brief Psychiatric Rating Scale (BPRS) score from baseline score at enrollment into the study. In cases where a patient was very close to the operational criteria for response ( $\geqslant 15 \%$ but $<20 \%$ ) but were clinically much improved, a reduction of at least one category on the Clinical Global Impressions (CGI) scale was considered in order to augment the definition of response; 8 of the 185 patients were classified as responders using this additional criterion. This definition of response was set a priori.

\section{Laboratory Methods}

Blood samples were collected from the clinical sites and sent to the Clarke Institute of Psychiatry in Toronto, Ontario, Canada. Genomic DNA was extracted from white blood cells using the high-salt method (Lahiri and Nurnberger 1991). All genotyping of the patients' DNA was performed at the Clarke Institute of Psychiatry, and laboratory staff were blind to the psychiatric ratings.

Three polymorphisms in HTR2A, one silent, one that alters the amino acid sequence, and one in its putative promoter region, as well as one putative functional polymorphism in HTR2C were examined in the clinical samples using the polymerase chain reaction and restriction fragment length polymorphism (PCR-RFLP) technique.

The silent $\mathrm{T} \rightarrow \mathrm{C} 102$ polymorphism at the HTR2A locus was genotyped employing a modified protocol of Warren et al. (1993). Primer sequences were the same as those

Table 1. Demographic Distribution from Each of the Clinical Sites

\begin{tabular}{|c|c|c|c|c|}
\hline & $\begin{array}{l}\text { Meltzer } \\
(n=105)\end{array}$ & $\begin{array}{l}\text { Lieberman } \\
(n=64)\end{array}$ & $\begin{array}{c}\text { Sevy } \\
(n=16)\end{array}$ & $\begin{array}{c}\text { Total } \\
(n=185)\end{array}$ \\
\hline $\operatorname{Age}^{a}($ Mean \pm SD $)$ & $32.5 \pm 8.9$ & $34.0 \pm 8.1$ & $40.1 \pm 9.4$ & $33.7 \pm 8.9$ \\
\hline \multicolumn{5}{|l|}{ Sex $^{b}$} \\
\hline Male & 75 & 41 & 16 & $132(71.4 \%)$ \\
\hline Female & 30 & 23 & 0 & $53(28.6 \%)$ \\
\hline \multicolumn{5}{|l|}{ Ethnicity } \\
\hline Caucasian & 79 & 53 & 12 & $144(77.9 \%)$ \\
\hline African American & 26 & 10 & 4 & $40(21.6 \%)$ \\
\hline Asian & 0 & 1 & 0 & $1(0.5 \%)$ \\
\hline \multicolumn{5}{|l|}{ Response } \\
\hline Responders & 51 & 37 & 9 & $97(52.4 \%)$ \\
\hline Nonresponders & 54 & 27 & 7 & $88(47.6 \%)$ \\
\hline
\end{tabular}


described by Warren et al. The PCR reaction was performed using $150 \mathrm{ng}$ of genomic DNA, $2.0 \mathrm{mM} \mathrm{MgCl}$, $0.4 \mu \mathrm{M}$ of both forward and reverse primer, $200 \mu \mathrm{M}$ each of 2'-deoxyadenosine-5'-triphosphate (dATP), 2'-deoxycytosine-5'-triphosphate (dCTP), 2'-deoxyguanosine$5^{\prime}$-triphosphate (dGTP), and 2'-deoxythymidine-5'-triphosphate (dTTP), and 1 unit of AmpliTaq DNA polymerase (Perkin-Elmer) in a final reaction volume of 25 $\mu l$. The PCR program consisted of 30 cycles of $94^{\circ} \mathrm{C}$ for $30 \mathrm{~s}, 61^{\circ} \mathrm{C}$ for $1 \mathrm{~min}$, and $72^{\circ} \mathrm{C}$ for $30 \mathrm{~s}$ with a final extension period of $72^{\circ} \mathrm{C}$ for 5 min using a GeneAmp 9600 Perkin-Elmer Cetus PCR machine. The PCR products were then restriction digested using $\mathrm{MspI}$ following manufacturer's protocol (New England Biolabs).

The his452tyr HTR2A PCR-RFLP was genotyped using a modified protocol of Erdmann et al. (1996). Primer sequences were the same as those described by Erdmann et al. The PCR reaction was performed using 150 ng of genomic DNA, $1 \mathrm{mM} \mathrm{MgCl} 2,0.6 \mu \mathrm{M}$ of both forward and reverse primer, $160 \mu \mathrm{M}$ each of dATP, dCTP, dGTP, and dTTP, and 1 unit of AmpliTaq DNA polymerase (Perkin-Elmer) in a final reaction volume of 25 $\mu l$. The PCR program consisted of 35 cycles of $95^{\circ} \mathrm{C}$ for $30 \mathrm{~s}, 58^{\circ} \mathrm{C}$ for $30 \mathrm{~s}$, and $72^{\circ} \mathrm{C}$ for $30 \mathrm{~s}$ with a final extension period of $72^{\circ} \mathrm{C}$ for 5 min using a GeneAmp 9600 Perkin-Elmer Cetus PCR machine. The PCR product was then digested with $B b v I$ restriction endonuclease (New England Biolabs).

The details of the HTR2A -1438 A $\rightarrow$ G promoter polymorphism were given to us by M. M. Nöthen (Nöthen et al. 1996 and personal communication). The sequence of the forward primer Pro2F is 5'-CTA GCC ACC CTG AGC CTA TG-3'; the sequence of the reverse primer Pro2R is $5^{\prime}$-TTG TGC AGA TTC CCA TTA AGG- $3^{\prime}$. The PCR reaction was performed using $150 \mathrm{ng}$ of genomic DNA, $1 \mathrm{mM} \mathrm{MgCl} 2,0.6 \mu \mathrm{M}$ of both forward and reverse primer, $160 \mu \mathrm{M}$ each of dATP, dCTP, dGTP, and dTTP, and 1 unit of AmpliTaq DNA polymerase (PerkinElmer) in a final reaction volume of $25 \mu$. The PCR program consisted of 30 cycles of $95^{\circ} \mathrm{C}$ for $30 \mathrm{~s}, 59^{\circ} \mathrm{C}$ for $30 \mathrm{~s}$, and $72^{\circ} \mathrm{C}$ for $30 \mathrm{~s}$ using a GeneAmp 9600 PerkinElmer Cetus PCR machine. The PCR product was then digested with MspI restriction endonuclease (New England Biolabs). After restriction digestion, the products were separated on a 3\% agarose gel by electrophoresis stained with ethidium bromide for UV visualization. An A at position -1438 leads to an uncut fragment of 200 base pairs (bp). A G at position -1438 leads to two fragments of length $121 \mathrm{bp}$ and $79 \mathrm{bp}$.

The cys23ser HTR2C PCR-RFLP was genotyped employing a modified protocol of Lappalainen et al. (1995). The primer sequences were the same as those described by Lappalainen et al. The PCR reaction was performed using $150 \mathrm{ng}$ of genomic DNA, $1.5 \mathrm{mM}$ $\mathrm{MgCl}_{2}, 0.6 \mu \mathrm{M}$ of both forward and reverse primer, 200 $\mu \mathrm{M}$ each of dATP, dCTP, dGTP, and dTTP, and 1 unit of AmpliTaq DNA polymerase (Perkin-Elmer) in a final reaction volume of $25 \mu$. The PCR program consisted of 35 cycles of $95^{\circ} \mathrm{C}$ for $30 \mathrm{~s}, 60^{\circ} \mathrm{C}$ for $30 \mathrm{~s}$, and $72^{\circ} \mathrm{C}$ for $30 \mathrm{~s}$ using a GeneAmp 9600 Perkin-Elmer Cetus PCR machine. Restriction digestion was performed using HinfI (New England Biolabs). All PCR products were separated by agarose gel electrophoresis ( $2 \%$ agarose for $\mathrm{T} \rightarrow \mathrm{C} 102 \mathrm{HTR} 2 \mathrm{~A}$; 3.5\% agarose for his452tyr HTR2A and cys23ser HTR2C) and stained with ethidium bromide for UV visualization.

\section{Statistical Methods}

The categorical data were analyzed using chi-square tests, and the continuous data; e.g., age, were analyzed using analysis of variance (ANOVA). The statistical program used was the Statistical Package for the Social Sciences (SPSS), version 7.0. Linkage disequilibrium was assessed using the linkage utility program, Equilibrium Haplotype (EH) (Terwilliger and Ott 1994), which employs a maximum likelihood method. Power analysis was performed using Epi Info, Version 5.01a (Public Domain Software for Epidemiology and Disease Surveillance, March 1991).

\section{RESULTS}

There were no significant differences in ethnicity and response rate between the patients from the three clinical sites. There was a significant difference observed between the mean age of the patients from the three clinical sites $[F(2,181)=5.06, p=.007]$; using Tukey's HSD test for post hoc comparisons, the mean ages of the Meltzer and Lieberman samples were significantly lower than that of the Sevy sample (see Table 1). There was also a significant difference in the proportion of males to females between the smaller sample (SS) and the two larger samples (HYM and JAL, see Table 1). The smaller sample consisted only of males $\left(\chi^{2}=8.09,2 \mathrm{df}\right.$, $p=.02$, two-tailed). The samples were combined into one group, and a total of 185 patients was evaluated; 132 men, 53 women; 144 Caucasians, 40 African Americans, 1 Asian; the mean age was 33.7 (SD 8.9) years. Of these, $97(52.4 \%)$ patients were considered responders to clozapine by the criteria cited above, and 88 (47.6\%) were not. In this combined sample, age, sex, and ethnicity factors were not different between responders and nonresponders to clozapine.

Genotype frequencies for the three polymorphisms in HTR2A did not differ significantly among patients from the different centers, between patients from different ethnic backgrounds, or between males and females. Genotype frequencies of the HTR2C polymorphism also did not differ significantly among patients from the different centers (hemizygous males and homozygous 
females were combined-for explanation see below). However, there was a significant difference between genotype frequencies of the HTR2C polymorphism and ethnic status $\left(\chi^{2}=16.87,2 \mathrm{df}, p<.0005\right.$ [two-tailed], see Table 3); African Americans had a significantly higher occurrence of the ser23 allele than did Caucasians.

For the silent $\mathrm{T} \rightarrow \mathrm{C} 102$ polymorphism in HTR2A, there were no significant differences observed in both allele and genotype counts between responders and nonresponders to clozapine (allele: $\chi^{2}=.02,1 \mathrm{df}, p=.90$ [two-tailed]; genotype: $\chi^{2}=.02,2 \mathrm{df}, p=.99$ [two-tailed], see Table 2a). We tested for Hardy-Weinberg equilibrium in both the responder and nonresponder groups and found no deviation for the $\mathrm{T} \rightarrow \mathrm{C} 102$ polymorphism in HTR2A. The $\mathrm{T} \rightarrow \mathrm{C} 102$ allele frequencies in the total sample were also similar to those reported by other groups. The novel $-1438 \mathrm{~A} \rightarrow \mathrm{G}$ HTR2A promoter polymorphism was in nearly full linkage disequilibrium with the $\mathrm{T} \rightarrow \mathrm{C} 102$ polymorphism $\left(\chi^{2}=305.79,1 \mathrm{df}, p<5 \times 10^{-7}\right)$. The disequilibrium coefficient $\delta$ for the haplotype $-1438 \mathrm{G}-\mathrm{C} 102$ was 0.24 . That is, almost every patient with a $\mathrm{C} 102$ allele had a $-1438 \mathrm{G}$ allele on the same chromosome. Thus, this promoter polymorphism measures virtually the same variation as $T \rightarrow C$ 102, and accordingly, the results with respect to clozapine response were similar (results not shown).

There were significant differences observed between responders and nonresponders to clozapine for the his452tyr polymorphism in HTR2A (see Table 2b). Allele counts for this polymorphism were significantly different between responders and nonresponders to clozapine $\left(\chi^{2}=6.43,1 \mathrm{df}, p=.01\right.$, two-tailed $[p=.04$, Bonferroni corrected], odds ratio for tyr452 association with nonresponse was 2.42 [95\% CI 1.15-5.32]). Patients who failed to respond had a tyr452 allele frequency of 0.15 , as compared to 0.07 in those who did respond. The Phi coefficient $\phi$ for this observed allelic association was equal to 0.13. Examining genotypes, individuals

Table 2a. Allele and Genotype Counts and Frequencies of the $\mathrm{T} \rightarrow \mathrm{C} 102$ Polymorphism in the 5-HT2A Receptor Gene in Clozapine-Treated Patients

\begin{tabular}{lccc}
\hline & Responders & Nonresponders & Total \\
\hline Allele $^{a}$ & & & \\
T102 & $86(45 \%)$ & $79(46 \%)$ & $165(46 \%)$ \\
C102 & $104(55 \%)$ & $93(54 \%)$ & $197(54 \%)$ \\
Total & 190 & 172 & 362 \\
Genotype & & & \\
T102/T102 & $19(20 \%)$ & $18(21 \%)$ & $37(21 \%)$ \\
T102/C102 & $48(51 \%)$ & $43(50 \%)$ & $91(50 \%)$ \\
C102/C102 & $28(29 \%)$ & $25(29 \%)$ & $53(29 \%)$ \\
Total & 95 & 86 & 181 \\
\hline
\end{tabular}

${ }^{a} \chi^{2}=0.02,1 \mathrm{df}, p=.90$ (two-tailed) for clinical response relative to allele counts (ODDS RATIO for C102 association to nonresponse $=0.97$; $95 \%$ CI $0.63-1.50)$.

${ }^{b} \chi^{2}=0.02,2 \mathrm{df}, p=.99$ (two-tailed) for clinical response relative to genotype counts. who did not respond to clozapine were more likely to be his/tyr 452 heterozygotes or tyr/tyr 452 homozygotes than those who did respond $\left(\chi^{2}=6.54,2 \mathrm{df}, p=\right.$ .04 , two-tailed $[p=.16$, Bonferroni corrected]). For this polymorphism, there was no deviation from HardyWeinberg equilibrium in both the responder and nonresponder groups. The allele frequencies in the total sample were also comparable to those published by others.

Examining two markers at a time, the level of disequilibrium between $\mathrm{T} \rightarrow \mathrm{C} 102$ and his452tyr was low and not statistically significant $\left(\chi^{2}=0.01,1 \mathrm{df}, p=.92\right)$; that between $\mathrm{T} \rightarrow \mathrm{C} 102$ and $-1438 \mathrm{~A} \rightarrow \mathrm{G}$ was statistically significant $\left(\chi^{2}=305.79,1 \mathrm{df}, p<5 \times 10^{-7}\right)$. Combining the markers, the level of linkage disequilibrium between these three HTR2A polymorphisms was high and statistically significant $\left(\chi^{2}=305.90,4 \mathrm{df}, p<5 \times\right.$ $10^{-7}$ ) with the major contribution coming from the high level of disequilibrium between $\mathrm{T} \rightarrow \mathrm{C} 102$ and -1438 $\mathrm{A} \rightarrow \mathrm{G}$. The disequilibrium coefficient $\delta$ for the haplotype $-1438 \mathrm{G}-\mathrm{C} 102-$ his 452 was 0.21 . To determine if a particular haplotype differentiated clozapine responders from nonresponders, we performed a haplotype analysis of these three HTR2A markers and response to clozapine. Under both dominant and recessive models, no haplotype association with response was found (dominant model: $p=.32$; recessive model: $p=.28$ ).

Because there was a significant difference between genotype frequencies of the HTR2C polymorphism and ethnic status, we analyzed clinical response to clozapine in Caucasians and African Americans separately. HTR2C is $\mathrm{X}$-linked, thus hemizygous males and homozygous females were grouped together because of inactivation of one of the $\mathrm{X}$ chromosomes in females. When the data were analyzed in this fashion (see Table 3), there were no significant differences observed between Caucasian responders and nonresponders to clozapine $\left(\chi^{2}=3.46,2\right.$ df, $p=.18$ two-tailed). This was also the same in the

Table 2b. Allele and Genotype Counts and Frequencies of the his452tyr Polymorphism in the 5-HT2A Receptor Gene in Clozapine-Treated Patients

\begin{tabular}{lccc}
\hline & Responders & Nonresponders & Total \\
\hline Allele $^{a}$ & & & \\
His452 & $177(93 \%)$ & $146(85 \%)$ & $323(89 \%)$ \\
Tyr452 & $13(7 \%)$ & $26(15 \%)$ & $39(11 \%)$ \\
Total & 190 & 172 & 362 \\
Genotype & & & \\
His/His 452 & $82(86 \%)$ & $63(73 \%)$ & $145(80 \%)$ \\
His/Tyr 452 & $13(14 \%)$ & $20(23 \%)$ & $33(18 \%)$ \\
Tyr/Tyr 452 & $0(0 \%)$ & $3(4 \%)$ & $3(2 \%)$ \\
Total & 95 & 86 & 181 \\
\hline
\end{tabular}

${ }^{a} \chi^{2}=6.43,1 \mathrm{df}, p=.01$ (two-tailed) ( $p=.04$, Bonferroni corrected) for clinical response relative to allele counts (ODDS RATIO for tyr452 association to non-response $=2.42 ; 95 \%$ CI 1.15-5.32).

${ }^{b} \chi^{2}=6.54,2 \mathrm{df}, p=.04$ (two-tailed) ( $p=.16$, Bonferroni corrected) for clinical response relative to genotype counts. 
group of African Americans when clozapine response was considered $\left(\chi^{2}=0.31,2 \mathrm{df}, p=.86\right.$, two-tailed). However, examination of the genotype distribution for both ethnic groups revealed a tendency for responders to be hemizygous or homozygous for the ser23 variant.

\section{DISCUSSION}

We have previously reported the lack of allelic association between the $\mathrm{T} \rightarrow \mathrm{C} 102$ polymorphism in HTR2A and clozapine response in a sample of clozapine-treated patients (Masellis et al. 1995). In the current study, we examined this polymorphism in an extended sample and, once again, report a lack of allelic association. Thus, we were not able to replicate the results of Arranz et al. (1995) who found that the homozygous genotype C102/C102 was more frequent in the nonresponders than in the responders to clozapine. Two other groups (Nöthen et al. 1995; Malhotra et al. 1996a) have also failed to replicate the finding of Arranz et al. (1995).

The $\mathrm{T} \rightarrow \mathrm{C} 102$ HTR2A polymorphism does not alter the predicted amino acid sequence of the receptor. One explanation for the discrepancy between our results and those of Arranz et al. (1995) might be that this silent HTR2A polymorphism is in linkage disequilibrium with a nearby polymorphism that is involved in clozapine response in the Arranz et al. (1995) sample, but not in our sample. This might be caused by differences in the populations from which the samples were collected. For example, the Arranz et al. (1995) sample consisted of Caucasian schizophrenia patients of Western European origin; whereas, our sample consisted of North American patients from a greater variety of ethnic backgrounds. It is important to consider that the ethnic diversity in our sample may have produced a type II error.
Alternatively, our failure to replicate Arranz and colleagues' (1995) finding may also be attributed to differences in the psychiatric rating scales used. We employed the Brief Psychiatric Rating Scale (BPRS), which is more focused on psychopathology than the Global Assessment Scale (GAS) used by Arranz et al. (1995). The GAS includes an assessment of social functioning in its ratings and this may be linked indirectly with psychopathology. The patients from the largest site $(n=$ 105; contributor HYM) in this study were also assessed with the GAS in addition to the BPRS. It was, therefore, possible in this group to employ the same criteria used by Arranz et al. (1995) to define response; that is, a 20point improvement in GAS score following clozapine treatment. According to the GAS criteria of Arranz et al., $18 \%$ of our patients (89 individuals; 16 individuals had GAS data missing) were responders to clozapine; whereas, $48.6 \%$ (105 individuals, total sample) were responders using our definition of response. Therefore, a smaller proportion of this patient sample (contributor HYM) responded to clozapine using the Arranz et al. GAS definition of response. The Arranz study used retrospective ratings and may have overestimated the extent of change for that reason. Although we do not have access to the GAS scores for our other two samples (contributors JAL, SS), these patients were clinically similar to the Meltzer sample. It may be appropriate to use multiple criteria for assessing outcome, because the genetic influence on outcome may be most important for only some of the relevant outcome measures; e.g., EPS, negative symptoms, or quality of life. A standard definition of antipsychotic response that includes multiple criteria should be agreed upon for use in future pharmacogenetic studies to attempt to control for this potential confounding factor.

We have found evidence suggestive of an association between the polymorphism that codes for a histidine to

Table 3. Genotype Counts and Frequencies of the cys23ser Polymorphism in the 5-HT2C Receptor Gene in Caucasian and African American Clozapine-Treated Patients

\begin{tabular}{|c|c|c|c|}
\hline & Responders & Nonresponders & Total $^{c}$ \\
\hline \multicolumn{4}{|c|}{ Genotype in Caucasians $^{a}$} \\
\hline Cys or Cys / Cys 23 & $55(76 \%)$ & $58(87 \%)$ & $113(81 \%)$ \\
\hline Cys/Ser 23 & $4(6 \%)$ & $4(6 \%)$ & $8(6 \%)$ \\
\hline Ser or Ser/Ser 23 & $13(18 \%)$ & $5(7 \%)$ & $18(13 \%)$ \\
\hline Total & 72 & 67 & 139 \\
\hline \multicolumn{4}{|c|}{ Genotype in African Americans ${ }^{b}$} \\
\hline Cys or Cys/Cys 23 & $9(45 \%)$ & $10(53 \%)$ & $19(49 \%)$ \\
\hline Cys/Ser 23 & $3(15 \%)$ & $3(16 \%)$ & $6(15 \%)$ \\
\hline Ser or Ser/Ser 23 & $8(40 \%)$ & $6(31 \%)$ & $14(36 \%)$ \\
\hline Total & 20 & 19 & 39 \\
\hline
\end{tabular}


tyrosine amino acid substitution at position 452 in the 5-HT2A receptor protein. We found that nonresponders to clozapine were more likely to possess the rarer tyr452 variant than those who responded to clozapine. This amino acid substitution occurs in the intracellular carboxyl-terminal tail of the 5-HT2A receptor protein. A substitution of a basic histidine residue for an uncharged polar tyrosine residue in the 5-HT2A receptor at this position may result in altered tertiary structure and possibly altered receptor function.

The carboxyl-terminal domain of G-protein coupled receptors has been implicated in phosphorylation-dependent desensitization (Hausdorff et al. 1990). Recently, Ozaki et al. (1997) have demonstrated that, in platelets from individuals possessing the different alleles, the tyr452 form of the 5-HT2A receptor protein may exist in a partially desensitized state as compared to the his 452 form. In his/tyr 452 heterozygotes, they found that tyr452 was associated with a smaller peak amplitude of $\mathrm{Ca}^{2+}$ mobilization after stimulation with serotonin compared to his452. Tyr452, as opposed to his452, was also found to be associated with a different time course of $\mathrm{Ca}^{2+}$ mobilization after stimulation with serotonin. We could speculate that these functional differences may account for the positive association observed here between this structural HTR2A variation and clozapine response. Alternatively, this particular variant may be in linkage disequilibrium with another site in HTR2A conferring response to clozapine. A false-positive result is also a possible explanation.

It is important to note here that the Phi coefficient $\phi$ of this allelic association was equal to 0.13 . This coefficient provides an estimate of the strength of the association between the tyr452 variant and nonresponse to clozapine. With respect to our demonstrated association, a $\phi$ of 0.13 suggests that there is only $13 \%$ agreement between the phenotype of nonresponse/response and the presence or absence of the tyr 452 variant, respectively. In other words, the association is modest, and $87 \%$ of the observed data cannot be accounted for by the relationship between the tyr452 variant and nonresponse to clozapine. Assuming our observed association was not a false positive, the small value of $\phi$ suggests that other factors are playing a role in the phenotype of clozapine response/nonresponse, possibly other polymorphisms.

Arranz et al. (1996) have recently reported a similar trend between this his452tyr HTR2A polymorphism and response to clozapine in their sample of Western European schizophrenia patients. The study of Malhotra et al. (1996a) did not support these results. Their failure to replicate the findings of Arranz et al. (1996), and those reported here may be attributable to differences in the clinical methods of the clozapine trials. First, the patient sample of Malhotra et al. was more clinically heterogeneous than ours, because their study included clozapine-treated patients with either DSM-III-R diagnoses of schizophrenia or schizoaffective disorder; it was also not clear if they were treatment-refractory or intolerant, and their sample size was substantially smaller $(n=70)$. Our study included only individuals who had DSM-III-R diagnoses of schizophrenia and who were treatment-refractory or intolerant to typical antipsychotic agents. Second, Malhotra et al. (1996a) assessed baseline BPRS scores after 4 weeks of clinical stabilization on a typical antipsychotic. Our sample of patients went through a washout period of 2 to 4 weeks, at which point baseline BPRS scores were assessed. Therefore, the mean baseline BPRS score of Malhotra et al. (1996a) may be lower than ours. Finally, their patient sample was treated with clozapine for only 10 weeks. All of our patients were maintained on clozapine treatment for a minimum of 6 months.

There is controversy surrounding the issue of the influence of duration of clozapine treatment and change in psychopathology. Meltzer (1989b; 1995b) has observed that some patients treated with clozapine may not reach criteria for response until after 6 months of treatment. Lieberman et al. (1994) also noted that some patients continue to improve on clozapine for up to a year and has supported the idea that the optimal period for a trial of clozapine is 12 to 24 weeks. On the other hand, Carpenter et al. (1995) have suggested that clozapine treatment be discontinued if no improvement is observed within several weeks. Approximately $40 \%$ of patients respond to clozapine with a $20 \%$ decrease in total BPRS score within the first 10 weeks of treatment assuming that: (1) the dose is increased at a reasonable rate; (2) the patients are not receiving typical antipsychotics concomitantly; (3) they are treatment-refractory to begin with; and (4) have baseline total BPRS scores $\geqslant 40$. Between 6 and 12 months of treatment, the response rate should approach $60 \%$. Assuming a high response rate of $40 \%$ in the first 10 weeks, anywhere from 10 to $20 \%$ of patients should subsequently respond to clozapine in the next 14 weeks. Lieberman et al. (1994) have also found that up to $20 \%$ of patients may respond after the initial 10 weeks of treatment. Based on this evidence, the proportion of responders vs. nonresponders will differ at 10 and 24 weeks, and thus the distribution of alleles in each of these groups may be significantly different from each other. This duration of treatment factor may contribute to the differences observed between our results and those of Malhotra et al. (1996a). In future pharmacogenetic studies, it seems appropriate that groups working in this field should agree upon a standard duration of time for clozapine treatment.

Our study is also different from others examining the pharmacogenetics of clozapine response in that our patients were prospectively followed up at regular intervals; whereas, the other studies were conducted retrospectively. These previous studies also did not report blood 
levels of clozapine such that poor compliance or subthreshold blood levels may have been confounding issues. The patients in our study had their clozapine blood levels carefully monitored at regular intervals to ascertain compliance and to ensure that threshold levels were achieved.

There was no association observed between any of the particular haplotype combinations of the HTR2A markers and response to clozapine. To our knowledge, this is the first haplotype analysis of HTR2A performed in a clozapine response sample looking specifically for a relationship between particular combinations of alleles and response to clozapine. Our results indicate that the only polymorphism contributing to the prediction of clozapine response was the his452tyr HTR2A structural polymorphism. No particular haplotype was associated with clozapine response under both dominant and recessive models.

We were not able to replicate the finding of Sodhi et al. (1995) who reported a positive association between the cys23ser amino acid substitution in the 5-HT2C receptor protein and clozapine response. Malhotra et al. (1996b) and Rietschel et al. (1997) also were not able to replicate this finding. Our failure to replicate may be attributable to the differences previously discussed between our study and that of Arranz et al. (1995).

Although we have failed to find a positive result between HTR2C and clozapine response, there was a tendency for responders to be either hemizygous or homozygous for the ser23 variant, and this was in the same direction as that reported by Sodhi et al. (1995). Further investigation of this variant is warranted because Goldman et al. (1995) have preliminary evidence suggesting that the ser23 HTR2C variant has altered affinity for the serotonergic agonist meta-chlorophenylpiperazine (mCPP) when compared to the cys 23 variant. It is possible that substitution of a cys 23 residue with a ser23 residue alters the tertiary structure of the 5-HT2C receptor protein by disrupting formation of protein-stabilizing disulfide bonds between cysteine residues; this may lead to altered receptor function.

To our knowledge, our study is the first to report differences between Caucasians and African Americans in the genotypic distribution of the cys23ser HTR2C polymorphism. Although replication in larger samples is needed to confirm this initial finding, this may be relevant to future studies examining differences in antipsychotic response across ethnic groups.

One of the most important limitations in studies of a complex trait such as clozapine response is sample size. It is difficult to collect large, well-characterized samples such as the one reported here. In addition, response to clozapine is thought to involve interaction with many different receptor sites and, thus, is likely to be genetically heterogeneous. Therefore, the ability to detect the effects of genes that play only a minor role in predicting response to clozapine is limited by this lack of statistical power. Allowing a type I error rate $(\alpha)=0.05$, power $(1-\beta)=0.80$, and pro- portion of the responders with the risk allele for nonresponse $\left(P_{0}\right)=0.60$, we can detect an odds ratio for the HTR2A C102 variant as low as 1.92 in our sample of clozapine-treated patients. Specifying the same $\alpha$ and power (1- $\beta$ ) with a $P_{0}=0.11$, we are able to detect an odds ratio for the HTR2A tyr452 variant as low as 2.33 in our sample. Thus, our sample has enough power to identify allelic variants in genes that may contribute in a more minor way to the total variance observed in clozapine response.

There were other limitations with our study. The most important was probably the ethnic composition of our sample. The patients were ascertained at three clinical sites in the United States and, as a result, our sample was ethnically heterogeneous. We tried to control for this confounding factor by ensuring that our responder and nonresponder rates were similar between Caucasians and African Americans. Also, we determined whether or not allele frequencies were different between ethnic groups; if so, we analyzed them separately. However, this does not exclude the possibility that our results were due to population stratification. Replication in independent samples is required to confirm our initial findings. These samples are currently in the process of being collected.

From these pharmacogenetic studies, one or more genetic factors may be discovered that play an important role in antipsychotic medication response. This genetic information may aid clinicians in deciding who should receive a particular drug, and it may also help in elucidating the mechanism of action of atypical antipsychotic agents. Ultimately, the genetic information may lead to the design of new, more specific therapeutic agents and may illuminate our understanding of the pathophysiology of schizophrenia.

\section{REFERENCES}

Arranz M, Collier D, Sodhi M, Ball D, Roberts G, Price J, Sham P, Kerwin R (1995): Association between clozapine response and allelic variation in 5-HT2A receptor gene. Lancet 346:281-282

Arranz MJ, Collier DA, Munro J, Sham P, Kirov G, Sodhi M, Roberts G, Price J, Kerwin RW (1996): Analysis of a structural polymorphism in the 5HT2A receptor and clinical response to clozapine. Neurosci Lett 217:177-178

Badri F, Masellis M, Petronis A, Macciardi FM, Van Tol HHM, Cola P, Meltzer HY, Lieberman J, Potkin S, Kennedy JL (1996): Dopamine and serotonin system genes may predict clinical response to clozapine. Abstract, $46^{\text {th }}$ Annual Meeting of the American Society of Human Genetics, San Francisco, 59:A247

Bersani G, Grispini A, Marini S, Pasini A, Valducci M, Ciani N (1986): Neuroleptic-induced extrapyramidal side effects: Clinical perspectives with ritanserin (R35667), A new selective 5-HT2 receptor blocking agent. Curr Ther Res 40:492-499

Bertilsson L, Carrillo JA, Dahi M-L, Llerena A, Alm C, Bondesson U, Lindstrom L, Rodriguez de Ia Rubia I, Ramos 
S, Benitez J (1994): Clozapine disposition covaries with CYP1A2 activity determined by a caffeine test. Br J Clin Pharmacol 38:471-473

Bleehen T (1993): Clozapine: Literature Review. Basle, Sandoz Pharma Ltd.

Bondesson U, Lindstrom LH (1988): Determination of clozapine and its $\mathrm{N}$-demethylated metabolite in plasma by use of spectrometry with single ion detection. Psychopharmacology 95:472-475

Canton H, Verriele L, Colpaert FC (1990): Binding of typical and atypical antipsychotics to 5HT1C and 5HT2 sites: Clozapine potently interacts with 5HT1C sites. Eur J Pharmacol 191:93-96

Carpenter WT, Conley RR, Buchanan RW, Breier A, Tamminga CA (1995): Patient response and resource management: Another view of clozapine treatment of schizophrenia. Am J Psychiatry 152:827-832

Cheng YF, Lundberg T, Bondesson U, Lindstrom L, Gabrielsson J (1988): Clinical pharmacokinetics of clozapine in chronic schizophrenic patients. Eur J Clin Pharmac 34:445-449

Choc M, Hsuan F, Honigfield G, Robinson W, Ereshefsky L, Crismon M, Saklad S, Hirschowitz J, Wagner R (1990): Single vs. multiple dose pharmacokinetics of clozapine in psychiatric patients. Pharm Res 4:347-351

Cholerton S, Daly AK, Idle JR (1992): The role of individual human cytochromes P450 in drug metabolism and clinical response. Trends Pharmacol Sci 13:434-439

Dahl ML, Bertilsson L (1993): Genetically variable metabolism of antidepressants and neuroleptic drugs in man. Pharmacogenetics 3:61-70

Dahl ML, Llerena A, Bondesson U, Lindstrom L, Bertilsson L (1994): Disposition of clozapine in man: lack of association with debrisoquine and S-mephenytoin hydroxylation polymorphisms. Br J Clin Pharmac 37:71-74

Erdmann J, Shimron-Abarbanell D, Rietschel M, Albus M, Maier W, Korner J, Bondy Brigitta B, Chen K, Shih JC, Knapp M, Propping P, Nöthen MM (1996): Systematic screening for mutations in the human serotonin-2A (5HT2A) receptor gene: Identification of two naturally occurring receptor variants and association analysis in schizophrenia. Hum Genet 97:614-619

Glennon RA, Titler M, McKenney JD (1984): Evidence of $5 \mathrm{HT} 2$ involvement in the mechanism of action of hallucinogenic agents. Life Sci 35:2505-2511

Goldman D, Lappalainen J, Ozaki N, Nakhai B, Bergen A. Pesonen U-M, Koulu M, Dean M, Zhang L, Weight F, Eggert M, Virkkunen M, Linnoila M (1995): Natural structural variants of human serotonin receptors. Abstract, World Congress on Psychiatric Genetics, Cardiff, UK, 5(suppl 1): S22

Hausdorff WP, Caron MG, Lefkowitz RJ (1990): Turning off the signal: Desensitization of beta-adrenergic receptor function. FASEB 4:2881-2889

Hoyer D, Clarke DE, Fozard JR, Hartig PR, Martin GR, Mylecharane EJ, Saxena PR, Humphrey PPA (1994): International Union of Pharmacology Classification of Receptors for 5-Hydroxytryptamine (Serotonin). Pharmacol Rev 46:157-203

Jerling M, Lindstrom L, Bondesson U, Bertilsson L (1994): Fluvoxamine inibition and Carbamazepine induction of the metabolism of Clozapine: Evidence from a therapeutic drug monitoring service. Therap Drug Monitoring 16:368-374

Kahn RS, Davidson M, Siever L, Gabriel S, Apter S, Davis KL (1993): Serotonin function and treatment response to clozapine in schizophrenia patients. Am Journal of Psychiatry 150(9):1337-1342

Kalow W (1986): Genetics of drug transformation. Clin Biochem 19:76-82

Kane J, Honigfield G, Singer J, Meltzer HY, the Clozaril Collaborative Study Group (1988): Clozapine for the treatment-resistant schizophrenic: A double-blind comparison with chlorpromazine. Arch Gen Psychiatry 45:789-796

Kennedy JL (1994): Prediction of neuroleptic response: Genetic strategies. In Gaebel W and Awad AG (eds), Prediction of Neuroleptic Treatment Outcome in Schizophrenia: Concepts and Methods. Wien, SpringerVerlag, pp 147-154

Kerwin RW, Pilowsky L, Munro J, Shaikh S, Gill M, Collier D (1994): Functional neuroimaging and pharmacogenetic studies of Clozapine's action at dopamine receptors. J Clin Psych 55:57-62

Kohn Y, Ebstein RP, HerescoLevy U, Shapira B, Nemanov L, Gritsenko I, Avnon M, Lerer B (1997): Dopamine D4 receptor gene polymorphisms: Relation to ethnicity, no association with schizophrenia and response to clozapine in Israeli subjects. Eur Neuropsychopharm 7:39-43

Lahiri DK and Nurnberger JI Jr (1991): A rapid non-enzymatic method for the preparation of HMV DNA from blood for RFLP analysis. Nucleic Acids Res 19:5444

Lappalainen J, Zhang L, Dean M, Oz M, Ozaki N, Yu D-H, Virkkunen M, Weight F, Linnoila M, Goldman D (1995): Identification, expression, and pharmacology of a Cys23Ser23 substitution in the human 5 -HT2C receptor gene (HTR2C). Genomics 27:274-279

Lieberman JA, Safferman AZ, Pollack S, Szymanski S, Johns C, Howard A, Kronig M, Bookstein P, Kane JM (1994): Clinical effects of clozapine in chronic schizophrenia: Response to treatment and predictors of outcome. Am J Psychiatry 151:1744-1752

Lindenmayer JP and Apergi FS (1996): The relationship between clozapine plasma levels and clinical response. Psych Ann 26(7):406-412

Malhotra AK, Goldman D, Ozaki N, Breier A, Buchanan R, Pickar D (1996a): Lack of association between polymorphisms in the 5-HT2A receptor gene and the antipsychotic response to clozapine. Am J Psych 153:1092-1094

Malhotra AK, Goldman D, Ozaki N, Rooney W, Clifton A, Buchanan RW, Breier A, Pickar D (1996b): Clozapine response and the 5HT2C Cys23Ser polymorphism. Neuroreport 7:2100-2102

Masellis M, Paterson AD, Badri F, Lieberman JA, Meltzer HY, Cavazzoni P, Kennedy JL (1995): Genetic variation of the 5-HT2A receptor and response to clozapine. Lancet 346:1108

Meltzer HY (1989a): Clinical studies on the mechanism of action of clozapine: The dopamine-serotonin hypothesis of schizophrenia. Psychopharmacology 99:S18-27

Meltzer HY (1989b): Duration of a clozapine trial in neuroleptic-resistant schizophrenia. Arch Gen Psychiatry 46:672 
Meltzer HY and Nash JF (1991) Effects of antipsychotic drugs on serotonin receptors. Pharmacol Rev 43:587-604

Meltzer HY (1994) An overview of the mechanism of action of clozapine. J Clin Psych 55:47-52

Meltzer HY (1995a) Role of serotonin in the action of atypical antipsychotic drugs. Clin Neurosci 3:64-75

Meltzer HY (1995b): Clozapine: Is another view valid? (editorial). Am J Psych 152:821-825

Meltzer HY (1996): Predictors of response to clozapine. Psych Ann 26:385-389

Nakajima M, Yokoi T, Mizutani M, Shin S, Kadlubar FF, Kamataki T (1994): Phenotyping of CYP1A2 in a Japanese population by analysis of caffeine urinary metabolites: Absence of mutation prescribing the phenotype in the CYP1A2 gene. Cancer Epidemiol Biomarkers Prev 3:413-421

Nöthen MM, Rietschel J, Erdmann J, Oberlander H, Moller HJ, Nober D, Propping P (1995): Genetic variation of the 5-HT2A receptor and response to clozapine. Lancet 346:908-909

Nöthen MM, Erdmann J, Shimron-Abarbanell D, Rietschel M, Albus M, Maier W, Chen K, Shih JC, Propping P (1996): Investigation of the serotonin 2A receptor gene in schizophrenia. Abstract, $46^{\text {th }}$ Annual Meeting of the American Society of Human Genetics San Francisco, 59:A230

Odom-White A, De Leon J (1996): Clozapine levels and caffeine. J Clin Psychiatry 57:175-176

Ozaki N, Manji H, Lubierman V, Lu SJ, Lappalainen J, Rosenthal NE, Goldman D (1997): A naturally occurring amino acid substitution of the human serotonin 5-HT2A receptor influences amplitude and timing of intracellular calcium mobilization. J Neurochemistry 68(5):2186-2193

Propping P, Nöthen MM (1995): Genetic variation of CNS receptors-A new perspective for pharmacogenetics. Pharmacogenetics 5:318-325

Rao PA, Pickar D, Gejman PV, Ram A, Gershon ES, Gelernter J (1994): Allelic variation in the D4 dopamine receptor (DRD4) gene does not predict response to clozapine. Arch Gen Psych 51:912-917

Rietschel M, Naber D, Oberlander H, Holzbach R, Fimmers R, Eggermann K, Moller HJ, Propping P, Nöthen MM (1996): Efficacy and side-effects of clozapine: Testing for association with allelic variation in the dopamine D4 receptor gene. Neuropsychopharmacology 15:491-496

Rietschel M, Naber D, Fimmers R, Moeller H-J, Propping P, Nöthen MM (1997): Efficacy and side effects of clozapine not associated with variation in the 5-HT2C receptor. Neuroreport 8:1999-2003

Rogue A, Rogue P (1992): Mianserin in the management of schizophrenia. In Schizophrenia, an International Conference Abstract Book. Vancouver, British Columbia, Canada, p. 135

Shaikh S, Collier D, Kerwin RW, Pilowsky LS, Gill M, Xu WM, Thornton A (1993): Dopamine D4 receptor subtypes and response to clozapine. Lancet 341:116

Shaikh S, Collier DA, Sham P, Pilowsky L, Sharma T, Lin LK, Crocq MA, Gill M, Kerwin R (1995): Analysis of clozapine response and polymorphisms of the dopamine D4 receptor gene (DRD4) in schizophrenic patients. Neuropsych Genetics 60:541-545

Sodhi MS, Arranz MJ, Curtis D, Ball DM, Sham P, Roberts GW, Price J, Collier DA, Kerwin RW (1995): Association between clozapine response and allelic variation in the 5-HT2C receptor gene. Neuroreport 7:169-172

Terwilliger JD and Ott J (1994): Handbook of Human Genetic Linkage. Baltimore, MD, The Johns Hopkins University Press

Thorup M and Fog R (1977): Clozapine treatment of schizophrenic patients. Plasma concentration and coagulation factors. Acta Psychiatr Scand 55:123-126

Van Tol HHM, Bunzow JR, Guan H-C, Sunahara RK, Seeman P, Niznik HB, Civelli O (1991): Cloning of the gene for a human dopamine D4 receptor with high affinity for the antipsychotic clozapine. Nature 350:610-614

Vojvoda D, Grimmell K, Sernyak M, Mazure C (1996): Monozygotic twins concordant for response to clozapine. Lancet 347:61

Warren JT Jr., Peacock ML, Rodriguez LC, Fink JK (1993): An MspI polymorphism in the human serotonin receptor gene (HTR2): Detection by DGGE and RFLP analysis. Hum Mol Genet 2:338

Wiesel F-A, Nordstrom A-L, Farde L, Eriksson B (1994): An open clinical and biochemical study of ritanserin in acute patients with schizophrenia. Psychopharmacology 114:31-38 